\title{
Flexible organic temperature sensors
}

\section{Daniela Topasna}

Daniela Topasna, "Flexible organic temperature sensors," Proc. SPIE 9665, Tenth International Topical Meeting on Education and Training in Optics and Photonics, 96651W (3 June 2007); doi: 10.1117/12.2207806

EDE Event: Tenth International Topical Meeting on Education and Training in Optics and Photonics, 2007, Ottawa, Ontario, Canada 


\section{Flexible Organic Temperature Sensors \\ Daniela Topasna et al \\ Virginia Military Institute \\ Lexington, VA}

The design and fabrication of thin film temperature sensors for various applications is an important and well established field. In order to gain familiarity with the design and fabrication of such devices, students at the Virginia Military Institute create and test their own thin film temperature sensors using organic polymers. The sensor is created by depositing a conducting polymer onto a flexible substrate with electrical contacts deposited by thermal evaporation. The resistance of the polymer as a function of temperature establishes a relationship that is then used to determine unknown resistances. 